\title{
Research of cyberspace situational factors organization criterion
}

\author{
Luo zi juan ${ }^{1,}$, wang cong lin ${ }^{2, b}$ \\ ${ }^{1}$ Science and Technology on Information Systems Engineering Laboratory, \\ NanJing,China \\ a48688489@qq.com bxxkywcl@126.com
}

Keywords: cyberspace ; organization criterion; situational factors, situational awareness

\begin{abstract}
This paper proposes a cyberspace situational factors organizational methods, provide a unified framework for data organization, so that information from different sources can be organized between the host status information to be consolidated, abnormal event information, traffic information, topology scan results and other data.
\end{abstract}

\section{Introduction}

With the rapid development and wide application of information technology network, in economic and social life of the great changes brought about development, network information in the field of virus attacks and malicious harm, but also for the development of the network running applications and socio-economic environment to bring extremely harmful effects, causing great loss of social and economic development. Especially in recent years, the network information technology application in social and economic development is more and more widespread and common cyberspace situational elements of the collection, extraction, processing network has also become a technical difficulty cyberspace posture ${ }^{[1-4]}$.

With the growing capability of technological means and, consequently, increasing the speed of military operations, information on the battlefield has become a valuable target for the military officers.

In this context, the Situational Awareness of modern combat aims to meet the needs of the Command and Control. In order to lead their military organizations, the commander would require concise information about his and the enemy troops. For example: What are the logistical needs? How to carry out an attack? What is the intention of the enemy?

\section{Cyberspace situational factors}

According to the requirements of cyberspace situational awareness, , situational factors include environmental factors and elements of the activity, and the activities involved in three aspects: goals, relationships, and events,, and activities related to the situation and therefore the elements from the target elements of the relationship between the elements and the event features three terms of extraction ${ }^{[5]}$. Among them, the environmental factors including geographical environment, network environment and electromagnetic environment; target elements include information systems, information flow, cyberspace weapons and combat personnel; factors include the physical connection between the relationship ${ }^{[6]}$, information exchange relations and social relations; event elements including other acts, events and results, including the four major data host status information, exception event information, traffic information, topology scan results and the like. In the handling and use of existing networks in cyberspace situational following questions: (1) data format is not unified, different types of trend data is difficult to compatible; (2) the user or system-demand, publishing, low ability to receive data (3) Process cumbersome storage, transport and use of trend data ${ }^{[7]}$. 


\section{Cyberspace situational factors organizational methods}

A common cyberspace situational factors of organization method includes the following four steps

First of all, according to user requirements extracted cyberspace situational factors (including the host state information, abnormal event information, traffic information, topological scans) ${ }^{[8]}$, these data packets of tissue specific elements of the organization in accordance with uniform methods. The paper is divided into five segments, respectively is: the main file header, host state information, abnormal event information, traffic information, topological scan results.

In the main file contained in the header fileid, version number, title, categories, packet length, the length of the message header ${ }^{[9]}$, the host state information description, abnormal event information description, scanning traffic information description, topology information description, etc. Master file header of each item of data are shown in table $1^{[10]}$.

Table 1 main file header

\begin{tabular}{|c|c|c|c|}
\hline Structure & type of data item meaning & length (characters) & Type \\
\hline \multirow[t]{2}{*}{$\begin{array}{l}\text { File begin } \\
\text { information }\end{array}$} & $\begin{array}{l}\text { File identification information. } \\
\text { Version } \\
\text { Generated by the date and time. } \\
\text { Format: CCYYMMDD hhmmss. } \\
\text { Which CC said century (00 to } 99 \text { ), YY } \\
\text { is said in the last two years ( } 00 \text { to } 99 \text { ), } \\
\text { the MM is in ( } 01 \text { to } 12) \text {, the DD is } \\
\text { date (01 to } 31 \text { ), hh is hours ( } 00 \text { to } 23) \text {, } \\
\text { the MM is minutes (00 to } 59 \text { ), ss ( } 00 \\
\text { to } 59 \text { ) is the second }\end{array}$ & $\begin{array}{l}4 \\
5\end{array}$ & $\begin{array}{l}\text { char[] } \\
\text { char[] }\end{array}$ \\
\hline & The title & 80 & char[] \\
\hline Security information & security & 1 & char[] \\
\hline \multirow{3}{*}{ File length } & The length of the message & 12 & UINT \\
\hline & The length of the message header & 6 & UINT \\
\hline & The main machine shape state & 3 & UINT \\
\hline \multirow{2}{*}{$\begin{array}{l}\text { The host state } \\
\text { information }\end{array}$} & $\begin{array}{c}\text { The length of the first host status } \\
\text { information }\end{array}$ & 10 & UINT \\
\hline & $\begin{array}{c}\mathrm{N} \text { the length of a host state } \\
\text { information }\end{array}$ & 10 & UINT \\
\hline \multirow{3}{*}{$\begin{array}{l}\text { Abnormal event } \\
\text { information }\end{array}$} & $\begin{array}{c}\text { The number of abnormal event } \\
\text { information }\end{array}$ & 3 & UINT \\
\hline & $\begin{array}{c}\text { The length of the abnormal event } \\
\text { information }\end{array}$ & 6 & UINT \\
\hline & $\begin{array}{l}\text { The first } \mathrm{n} \text { the length of the abnormal } \\
\text { event information }\end{array}$ & 6 & UINT \\
\hline \multirow{3}{*}{ Traffic information } & \multirow{3}{*}{$\begin{array}{l}\text { The number of traffic information } \\
\text { The length of the flow of information } \\
\text { The first } n \text { the length of the flow of } \\
\text { information }\end{array}$} & 3 & UINT \\
\hline & & 5 & UINT \\
\hline & & 5 & UINT \\
\hline \multirow{3}{*}{ Topology scans of data } & $\begin{array}{c}\text { Above topology scanning information } \\
\text { quantity }\end{array}$ & 3 & UINT \\
\hline & $\begin{array}{l}\text { The length of the scanning first } \\
\text { topology information }\end{array}$ & 2 & UINT \\
\hline & $\begin{array}{c}\text { The length of the first data extension } \\
\text { jokes head }\end{array}$ & 2 & UINT \\
\hline
\end{tabular}


The host state information of data items such as table 2 .

Table2 host state information of data items

\begin{tabular}{|c|c|c|c|}
\hline Data item meaning & length (bytes) & describe & types \\
\hline The port number & 4 & service port & UINT \\
\hline Service agreement & 64 & Service agreement & char[] \\
\hline Service name & 64 & Service agreement & char[] \\
\hline Service object & 64 & Service object & char[] \\
\hline service function & 64 & service function & char[] \\
\hline Service type & 32 & Service type & $\operatorname{char}[]$ \\
\hline Vulnerability port number & 4 & port & UINT \\
\hline Vulnerability names & 64 & Vulnerability names & char[] \\
\hline Vulnerability describes & 64 & $\begin{array}{l}\text { Vulnerability } \\
\text { describes }\end{array}$ & char[] \\
\hline Hole type & 32 & Hole type & char[] \\
\hline CPU information & 8 & CPU percentage & FLOAT \\
\hline Memory information & 8 & $\begin{array}{l}\text { Memory usage } \\
\text { percentage }\end{array}$ & FLOAT \\
\hline information of abnormal process & 32 & abnormal process & char[] \\
\hline Other & 32 & $\begin{array}{l}\text { other exception } \\
\text { information }\end{array}$ & char[] \\
\hline
\end{tabular}

Abnormal event information of data items are shown in table 3.

Table3 Abnormal event information of data items

\begin{tabular}{cccc}
\hline Data item meaning & length (bytes) & describe & types \\
\hline security incident ID & 8 & event ID & ULONG \\
Event time & 8 & safety incident & ULONG \\
Event name & 64 & security event name & char[] \\
Describe & 64 & security events description & char[] \\
source IP & 4 & event source IP & UINT32 \\
Source port & 4 & event source port & UINT32 \\
Destination IP & 4 & Event Destination IP & UINT32 \\
Destination port & 4 & Event Destination port & UINT32 \\
\hline
\end{tabular}

Traffic information of data items are shown in table 4.

Table4 Traffic information of data items

\begin{tabular}{|c|c|c|c|}
\hline Data item meaning & length (bytes) & describe & types \\
\hline Source IP & 4 & data flow transmission & UINT32 \\
\hline source port & 4 & $\begin{array}{c}\text { data flow transmission source } \\
\text { port }\end{array}$ & UINT32 \\
\hline Destination IP & 4 & $\begin{array}{c}\text { data flow transmission } \\
\text { purposes }\end{array}$ & UINT32 \\
\hline Destination port & 4 & $\begin{array}{c}\text { data flow transmission } \\
\text { purposes }\end{array}$ & UINT32 \\
\hline Flow & 4 & data flow & UINT32 \\
\hline $\begin{array}{l}\text { Protocol } \\
\text { application }\end{array}$ & 64 & layer protocol for the data flow & char[] \\
\hline Features & 64 & destination IP & char[] \\
\hline
\end{tabular}

Topology scans of data items in table 5. 
Table5 Topology scans of data items

\begin{tabular}{cccc}
\hline Data item meaning & length (bytes) & describe & types \\
\hline The main object of type & 4 & identified main type & UNIT \\
Subtype & 4 & identified object subtype & UNIT \\
Node ID & 4 & identified node ID & UNIT \\
node name & 32 & node name & string \\
node description & 64 & node description & string \\
The parent node ID & 4 & The parent node ID & Unit \\
The unit & 64 & nodes belong name & string \\
Topology position & 4 & topology view the location & double \\
geographical position & 4 & geographical position & double \\
\hline
\end{tabular}

\section{Situation transmission element method}

Cyberspace situational intelligence data packaged into a common message format main steps include:

1) The format of the host state information as defined in Table 2 are sequentially written messages;

2) abnormal event information in accordance with the format defined in Table 3 are sequentially written messages;

3) The format of the topology scan result information defined in Table 4 are sequentially written messages;

4) the corresponding information file format in Table 1 are sequentially written into the main file header packets in.

After the user receives the packet, the first packet network in accordance with specification is converted into cyberspace situational intelligence data. The main steps include:

1) Read from the message out situational intelligence data master file header;

2) Read from the message out host status information;

3) Read the abnormal event information from the packet;

4) to read out the topology scan results from the packet;

5) Read out traffic information from the packet;

From the foregoing, Universal Cyberspace situational factors organizational methods of the present invention to meet the different departments, users and system "on-demand package" and "on-demand extraction of" relevant situation requires unusual events and elements for cyberspace situational network release and use of the feature.

\section{Conclusion}

Compared with the prior art, the significant advantages: 1) Cyberspace situational elements of the organization process of the present invention, can be packaged into a unified multi-class elements of a particular form of packets, applicable to many types of trend products; 2) The present invention realizes transmission diversity of content, the use of many types of data (host status information, exception event information, traffic information, topology scan results information), integrated express network electromagnetic spatial elements; 3) The present invention enables flexible transmission nature: for different user needs, users can "demand package", "on-demand extract" interesting intelligence data; 4) the invention achieves the transmission of simplicity: a small data formatting processing cost, the user can in the limited bandwidth conditions By handling and use of intelligence products. 


\section{Reference}

[1] $\mathrm{Xu}$ Bo quan,WangHeng,Zhou Guangxia. Understanding and studying Cyberspace [J].Command Information System and Technology ,2010,1(1):23-26.(inChinese)

[2] Zhou Guangxia Wang Jing Zhao Xi. Development Trend of U.S.Military Cyberspace and Its Enlightenment[J] Command Information System and Technology,2015,6(1):1-5.(in Chinese)

[3] U.S. Army Capabilities Integration Center.Cyberspace operations concept capability plan 2016-2028[R].Washington D.C.: Department of the Army,2010.

[4] Naval Operations for Information Dominance, U.S. fleet Cyber command.Navy Cyber power 2020[R].Washington D.C.: Department of the Navy,2012.

[5] Office of the USAF Chief Scientist. Cyber vision 2025[R]. Washington D.C.: Department of the AirForce,2012.

[6] Zhuo Y, Zhang Q, Gong ZH. Research and implementation of network transmission situation awareness. In: Proc. of the CSIE. Los Angeles, 2009. 210-214. http://ieeexplore.ieee.org/

[7] Sun JG, Liu J, Zhao LY. Clustering algorithms research. Journal of Software, 2008,19(1):48-61

(in Chinese with English abstract). http://www.jos.org.cn/1000-9825/19/48.htm [doi: 10.3724/ SP. J.10 01. 2008.00048$]$

[8] Bass T, Robichaux R. Defense-in-Depth revisited: Qualitative risk analysis methodology for complex network-centric operations.In: Proc. of the Communications for Network-Centric Operations: Creating the Information Force (MILCOM). IEEE, 2001. 64-70. http: // citeseerx.ist.psu.edu/viewdoc/download?doi=10.1.1.65.5445\&rep=rep1\&type=pd

[9] Wei Y, Lian YF, Feng GD. A network security situational awareness model based on information fusion. Journal of Computer Research and Development, 2009,46(3):353-362 (in Chinese with English abstract).

[10]Wei Y, Lian YF. A network security situational awareness model based on log audit and performance correction. Chinese Journal of Computers, 2009,32(4):763-772 (in Chinese with English abstract). 